\title{
Comparison of restrictive fluid therapy with goal-directed fluid therapy for postoperative delirium in patients undergoing spine surgery: a randomized controlled trial
}

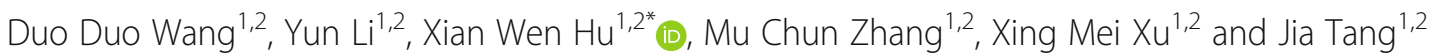

\begin{abstract}
Background: Postoperative delirium (POD) is a common phenomenon after spinal surgery. Intraoperative fluid management may affect POD. The aim of this study was to compare the effects of restrictive fluid therapy (RF) with those of goal-directed fluid therapy (GDT) on POD.

Methods: A total of 195 patients aged $\geq 50$ years who underwent spinal surgery were randomly divided into two groups: the RF group and the GDT group. In group RF, a bolus of lactated Ringer's solution was administered at a dose of $5 \mathrm{~mL} \cdot \mathrm{kg}^{-1}$ before the induction of anesthesia, followed by a dose of $5 \mathrm{~mL} \cdot \mathrm{kg}^{-1} \cdot \mathrm{h}^{-1}$ until the end of surgery. For patients in the GDT group, in addition to the initial administration of lactated Ringer's solution at $5 \mathrm{~mL} \cdot \mathrm{kg}^{-1}$, the subsequent fluid therapy was adjusted by using a continuous noninvasive arterial pressure (CNAP) monitoring system to maintain pulse pressure variation (PPV) $\leq 14 \%$. The primary endpoint was the incidence of POD, assessed once daily with the Confusion Assessment Method-Chinese Reversion (CAM-CR) scale at 1-3 days postoperatively. The secondary endpoints were intraoperative fluid infusion volume, urine volume, mean arterial pressure (MAP), heart rate $(\mathrm{HR})$, cardiac index $(\mathrm{Cl})$, regional cerebral oxygen saturation $\left(\mathrm{rSO}_{2}\right)$ value, lactic acid value, and visual analog scale (VAS) pain score at 1-3 days after surgery. Moreover, postoperative complications and the length of hospital stay were recorded.
\end{abstract}

\footnotetext{
*Correspondence: huxianwen001@163.com

'Department of Anesthesiology, The Second Hospital of Anhui Medical University, 678 Furong Road, Economic Development Zone, Hefei City 230032, Anhui Province, China

${ }^{2}$ Key Laboratory of Anesthesiology and Perioperative Medicine of Anhui Higher Education Institutes, Anhui Medical University, Hefei city 230032, Anhui, China
}

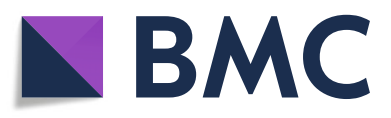

(c) The Author(s). 2021 Open Access This article is licensed under a Creative Commons Attribution 4.0 International License, which permits use, sharing, adaptation, distribution and reproduction in any medium or format, as long as you give appropriate credit to the original author(s) and the source, provide a link to the Creative Commons licence, and indicate if changes were made. The images or other third party material in this article are included in the article's Creative Commons licence, unless indicated otherwise in a credit line to the material. If material is not included in the article's Creative Commons licence and your intended use is not permitted by statutory regulation or exceeds the permitted use, you will need to obtain permission directly from the copyright holder. To view a copy of this licence, visit http://creativecommons.org/licenses/by/4.0/ The Creative Commons Public Domain Dedication waiver (http://creativecommons.org/publicdomain/zero/1.0/) applies to the data made available in this article, unless otherwise stated in a credit line to the data. 
Results: The incidence of POD was lower in the GDT group than in the RF group (12.4\% vs 4.1\%; $P=0.035$ ) in the first 3 days after spine surgery. Compared to group RF, group GDT exhibited a significantly increased volume of intraoperative lactated Ringer's solution [1500 (interquartile range: 1128 to 1775) $\mathrm{mL}$ vs 1000 (interquartile range: 765 to 1300$) \mathrm{mL}, P<0.001$ ] and urine volume [398 (interquartile range: 288 to 600 ) $\mathrm{mL}$ vs 300 (interquartile range: 200 to 530$) \mathrm{mL}, P=0.012]$. Intraoperative MAP, $\mathrm{Cl}$ and $\mathrm{rSO}_{2}$ values were higher in the GDT group than in the RF group $(P<0.05)$. Moreover, the length of hospital stay [17.0 (14 to 20$)$ days versus 14.5 (13 to 17.0) days, $P=0.001$ ] was shorter in the GDT group than in the RF group.

Conclusions: GDT reduced the incidence of POD in middle- and old-aged patients undergoing spinal surgery possibly by stabilizing perioperative hemodynamic and improving the supply and demand of oxygen.

Trial registration: ChiCTR2000032603; Registered on May 3, 2020.

Keyword: Restrictive fluid therapy, Goal-directed fluid therapy, Spinal surgery, Postoperative delirium

\section{Introduction}

Postoperative delirium (POD), an acute condition characterized by reduced awareness of the environment and a disturbance in attention, typically occurs between 24 and $72 \mathrm{~h}$ after surgery (American Society of Psychiatrists.DSM-5 Criteria for Delirium 2013; Miller et al. 2018). A previous study suggested that the incidence of POD in patients undergoing spinal surgery is up to $40.5 \%$ for older adults (Brown et al. 2016) and approximately $9.3 \%$ for middle- and old-aged adults (Jiang et al. 2017). The consequences of POD can be profound, including an increased risk of prolonged hospitalization and need for extended care, resulting in functional decline, postoperative cognitive dysfunction, and increased mortality (Witlox et al. 2010; Aitken et al. 2017). The risk of POD is multifactorial. Some studies and consensus-based guidelines on POD have suggested that POD may be the result of pathological changes in the central nervous system induced and aggravated by operative trauma, anesthesia-related stress, and other external factors, which are related to changes in the tissue perfusion and brain oxygen supply during the perioperative period (Hughes et al. 2012; Aldecoa et al. 2017; Cascella et al. 2018).

Intraoperative fluid management is considered an important factor affecting the tissue perfusion and brain oxygen supply in surgical patients (Makaryus et al. 2018). The amount of intraoperative fluid management has been described as a modifiable risk factor of POD (Brown et al. 2016; Mailhot et al. 2019). Some studies have demonstrated that aggressive or "liberal" intraoperative fluid therapy is linked to increased postoperative complications and length of hospital stay in patients undergoing spine surgery, and additional evidence has suggested that more restrictive fluid protocol leads to fewer complications and a shorter hospital stay (Siemionow et al. 2012a, b; Hart et al. 2013). However, overly restricted or inadequate fluid therapy leads to hypotension, organ hypoperfusion with successive organ dysfunction and failure, and even adverse outcomes (Schol et al. 2016; Myles et al. 2019), which will increase the complication rate, hospital stay, and mortality.

Recently, goal-directed fluid therapy (GDT), defined as the deliberate and individualized optimization of hemodynamics and oxygen delivery using fluid and/or vasoactive infusions, has been proposed (Makaryus et al. 2018). GDT, guided by dynamic indicators of fluid responsiveness (e.g., pulse pressure variation, PPV), has been shown to decrease postoperative complications and to shorten the length of stay during major abdominal surgery (Coeckelenbergh et al. 2019). Compared with traditional fluid therapy, GDT can effectively maintain the stability of perioperative hemodynamics, optimize the relationship between tissue perfusion, and may reduce the incidence of POD in spinal surgery (Zhang et al. 2018).

However, few studies have examined the comparative outcome performances of restrictive and GDT in major spinal surgery. Therefore, we conducted a prospective, randomized, controlled trial to compare the incidence of POD in patients who were undergoing elective major spinal surgery with either intraoperative restrictive or GDT.

\section{Materials and methods \\ Study design}

This randomized clinical study was performed according to the Declaration of Helsinki principles between May 2020 and November 2020 in the Second Affiliated Hospital of Anhui Medical University. The study was approved by the Ethics Committee for Clinical Trials of the Second Affiliated Hospital of Anhui Medical University, Hefei, China [approval no.: PJ-YX2019-052(F2)]. The trial was registered in the Chinese Clinical Trial Registry before patient enrollment (ChiCTR2000032603). Written informed consent was obtained from each subject.

Inclusion criteria: (1) Age $\geq 50$ years old, (2) lumbar spine and/or thoracic spinal stenosis surgery, (3) 
American Society of Anesthesiologists (ASA) grade of III, (4) body mass index (BMI) $<30 \mathrm{~kg} \cdot \mathrm{m}^{-2}$, (5) preoperative hematocrit $>0.30$, (6) effective communication with the physician. Exclusion criteria: (1) patients with a history of mental illness or neurological disease; (2) patients receiving drugs that may affect cognitive function; (3) patients with visual, auditory, or language communication disorders; (4) patients with liver and kidney dysfunction and severe cardiopulmonary disease; and (5) patients who failed to pass the preoperative simple minimental state scale (MMSE) exam (patients with illiteracy who obtained a score $\leq 17$, patients with $1-6$ years of education who obtained a score $\leq 20$, patients with greater than 7 years of education who obtained a score $\leq$ 23) (Li et al. 2016).

A statistician, who was independent of data management and statistical analyses, generated random numbers (in a 1:1 ratio) using the SPSS 21.0 (SPSS Inc., Chicago, IL, USA). The results of randomization were sealed in sequentially numbered envelopes and stored at the site of the investigation until interventions were assigned. After enrollment, patients were randomly divided into a restrictive fluid therapy (RF) group and a GDT group using a computer-generated randomization table. Randomization was assigned in a 1:1 ratio to a trial group. An anesthesiologist administered the study intervention according to the randomization sequence. The anesthesiologist was not blinded to the trials because he/ she was responsible for the delivery of the intervention. Outcome assessments and statistical analyses were performed by blinded researchers. The patients, outcome assessor, and surgical team were blinded to the study allocation status of the participants.

\section{Management of general anesthesia and analgesia}

All patients fasted for $8 \mathrm{~h}$ and did not receive any sedative or analgesic medications before the induction of anesthesia. After entering the operating room, peripheral venous infusion of the upper limbs and radial arterial lines was established. The multifunctional monitor (model: infinityC700, Germany, Draegerwerk AG\&CO. $\mathrm{KGaA}$ ) was used to continuously monitor the heart rate (HR), arterial blood pressure, mean arterial pressure (MAP), oxygen saturation $\left(\mathrm{SpO}_{2}\right)$, and bispectral index (BIS). For BIS monitoring, a disposable BIS sensor (BIS $^{\mathrm{TM}}$ sensor; America, Covidien IIc Co.) was applied to the forehead after the skin was wiped with alcohol swabs. PPV, cardiac index (CI), and stroke volume (SV) were monitored with the continuous noninvasive arterial pressure monitoring system (CNAP) (model: CANP ${ }^{\mathrm{mi}}$ Monitor 500, Guangzhou Xinju Science and Trade Co.). For measuring $\mathrm{rSO}_{2}$, two sensors for near-infrared spectroscopy (model: egos-600a, Suzhou Aiqin Bio-Medical Electronics Co.) were pasted on the left and right sides of the forehead. The patient's baseline $\mathrm{rSO}_{2}$ data were acquired before anesthetic induction while he/she breathed room air.

One hundred percent oxygen was provided with a mask before intubation. General anesthesia was induced with sufentanil $0.5 \mu \mathrm{g} \cdot \mathrm{kg}^{-1}$, etomidate $0.2 \mathrm{mg} \cdot \mathrm{kg}^{-1}$, and rocuronium $0.6 \mathrm{mg} \cdot \mathrm{kg}^{-1}$. After successful intubation, all patients received volume-controlled mechanical ventilation with $8 \mathrm{~mL} \cdot \mathrm{kg}^{-1}$ of tidal volume and an inspiratoryto-expiratory ratio of $1: 2$, and the respiratory rate was adjusted to maintain the end-tidal pressure of carbon dioxide $\left(\mathrm{P}_{\mathrm{ET}} \mathrm{CO}_{2}\right)$ concentration at 35 to $45 \mathrm{mmHg}$. Anesthesia was maintained with sevoflurane inhalation (1-2\%) in a $2 \mathrm{~L} 50 \%$ oxygen/air mixture, as well as continuous intravenous (IV) propofol (4-8 $\mathrm{mg} \cdot \mathrm{kg}^{-1} \mathrm{~h}^{-1}$ ), remifentanil $\left(0.1-0.3 \mu \mathrm{g} \cdot \mathrm{kg}^{-1} \cdot \mathrm{min}^{-1}\right)$, and cisatracurium (0.1-0.2 $\mathrm{mg} \cdot \mathrm{kg}^{-1} \mathrm{~h}^{-1}$ ) infusions to keep the BIS values between 40 and 60 . The patient's body temperature was monitored by a nasal thermometer (Shen Zhen, Mecun, Healthcare Co.) and maintained between $36.0^{\circ} \mathrm{C}$ and $37.0^{\circ} \mathrm{C}$. Cisatracurium and sevoflurane were terminated approximately $30 \mathrm{~min}$ before the end of the surgery, and $10 \mu \mathrm{g}$ sufentanil was administered approximately $30 \mathrm{~min}$ before skin closure. Propofol and remifentanil were discontinued at the end of the surgery. After surgery, early recovery was managed in the postanesthesia care unit (PACU), and patients were sent back to the ward with a Steward resuscitation score above 4 (Steward 1975). All patients used intravenous patient-controlled analgesia postoperatively for $48 \mathrm{~h}$. The IV patient-controlled analgesia consisted of $2.5 \mu \mathrm{g} \cdot \mathrm{kg}^{-1}$ sufentanil and $2 \mathrm{mg}$ granisetron (total volume of $100 \mathrm{~mL}$, including $0.9 \%$ normal saline, basal rate with $0.05 \mu \mathrm{g} \cdot \mathrm{kg}^{-1} \cdot \mathrm{h}^{-1}$ sufentanil and $0.04 \mathrm{mg} \cdot \mathrm{h}^{-1}$ granisetron, bolus with $0.05 \mu \mathrm{g} \cdot \mathrm{kg}^{-1}$ sufentanil and $0.04 \mathrm{mg}$ granisetron, and lockout time $15 \mathrm{~min}$ ).

\section{Perioperative fluid and hemodynamic management}

RF was designed to a bolus of lactated Ringer's solution with a dose of $5 \mathrm{~mL} \cdot \mathrm{kg}^{-1}$ before the induction of anesthesia, followed by a dose of $5 \mathrm{~mL} \cdot \mathrm{kg}^{-1} \cdot \mathrm{h}^{-1}$ until the end of surgery. Hypotension (hypotension was defined as MAP $\leq 60 \mathrm{mmHg}$ and/or systolic pressure $\leq 90$ $\mathrm{mmHg}$ for more than $5 \mathrm{~min}$ ) was initially treated in the form of an ephedrine bolus of $6 \mathrm{mg}$ with a maximal cumulative dose of $30 \mathrm{mg}$. If needed, a continuous infusion of norepinephrine $\left(0.05 \mu \mathrm{g} \cdot \mathrm{kg}^{-1} \cdot \mathrm{min}^{-1}\right)$ was administered (Picard et al. 2016). If hypotension did not respond to vasopressors, fluid boluses of $3 \mathrm{~mL} \cdot \mathrm{kg}^{-1}$ of lactated Ringer's solution were given.

Patients in group GDT received the fluid management depicted in Fig. 1. The GDT group had a bolus of lactated Ringer's solution at a dose of $5 \mathrm{~mL} \cdot \mathrm{kg}^{-1}$ before the induction of anesthesia, followed by a dose of 5 $\mathrm{mL} \cdot \mathrm{kg}^{-1} \cdot \mathrm{h}^{-1}$. Under the control of the CNAP system, 


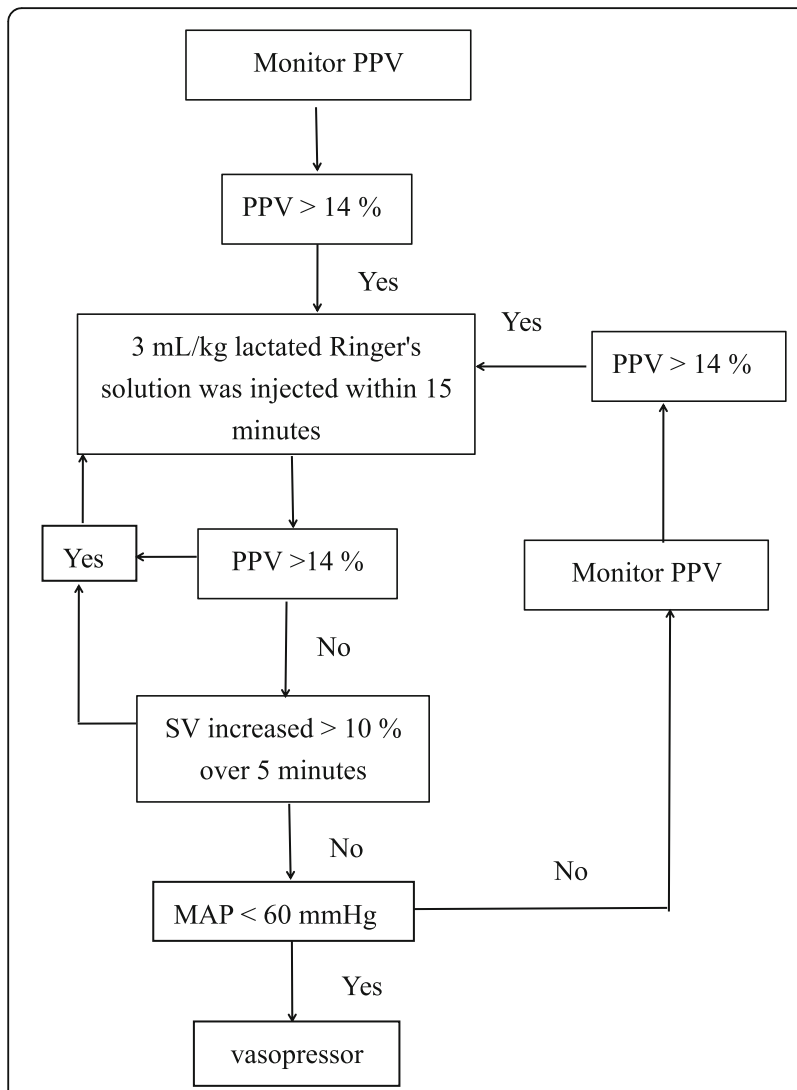

Fig. 1 Flow of GDT. PPV pulse pressure variation, SV stroke volume, MAP mean arterial pressure

each time, $3 \mathrm{~mL} \cdot \mathrm{kg}^{-1}$ of lactated Ringer's solution within 15 min was injected to maintain PPV $\leq 14 \%$. When the measured PPV was greater than $14 \%$ (for $5 \mathrm{~min}$ ) or when SV increased more than $10 \%$, another $3 \mathrm{~mL} \cdot \mathrm{kg}^{-1}$ of lactated Ringer's solution was given until PPV $\leq 14 \%$ was realized. The intervention was repeated when PPV remained $>14 \%$ following the fluid bolus. When MAP remained $<60 \mathrm{mmHg}$ despite the fluid intervention or MAP was $<60 \mathrm{mmHg}$ with PPV $\leq 14 \%$ and SV increased less than $10 \%$, vasopressor therapy was initiated, in the form of an ephedrine bolus of $6 \mathrm{mg}$ with a maximal cumulative dose of $30 \mathrm{mg}$. If needed, a continuous infusion of norepinephrine $\left(0.05 \mu \mathrm{g} \cdot \mathrm{kg}^{-1} \cdot \mathrm{min}^{-1}\right)$ was administered (Hasanin et al. 2019).

Blood loss in all patients was replaced with hydroxyethyl starch 130/0.4 sodium chloride injection (HES) at a 1:1 ratio, and blood transfusion was started when clinically indicated and supported by laboratory evidence of hemoglobin less than $70 \mathrm{~g} \cdot \mathrm{L}^{-1}$. Postoperative fluids for both groups followed an identical regimen: a maintenance rate of $0.5 \mathrm{~mL} \cdot \mathrm{kg}^{-1} \cdot \mathrm{h}^{-1}$ lactated Ringer's solution (minimum $40 \mathrm{~mL} \cdot \mathrm{h}^{-1}$ ) for the $6 \mathrm{~h}$ after the operation with additional boluses allowed for hypotension, or urine output $<0.5 \mathrm{~mL} \cdot \mathrm{kg}^{-1} \cdot \mathrm{h}^{-1}$ for $4 \mathrm{~h}$.

\section{Outcome measures}

The primary endpoint was the incidence of POD at $1-3$ days after surgery, which was evaluated once daily at the same time in the afternoon by the same systematic training member who was blinded to the group assignment. POD was assessed with the Confusion Assessment Method-Chinese Revision (CAM-CR) scale, which used the original 11 items of the CAM but developed a 4point evaluation for each item (Juan et al. 2003; Guo et al. 2017). The items of CAM-CR include acute onset, attention deficit, disorientation, memory deficit, perceptual deficit, excitement, hysteresis, fluctuation of illness, and change in the sleep-wake cycle. Assessment criteria were as follows: a score of $<19$ points indicated that the patient did not have delirium, a score of $20-22$ points indicated that the patient had suspected delirium, and a score of $>22$ points indicated that the patient had delirium.

The total intraoperative fluid infusion volume (including lactated Ringer's solution and HES), urine volume, estimated blood loss volume (including the blood collected during cell saver and suction canisters), patients received packed red blood cells, cell saver blood administered volume, and dose of vasoactive agents were recorded during the operation. $\mathrm{HR}, \mathrm{MAP}, \mathrm{CI}$, and $\mathrm{rSO}_{2}$ were recorded at $5 \mathrm{~min}$ before the induction of anesthesia $\left(\mathrm{T}_{0}\right) ; 5$ min after induction of anesthesia $\left(\mathrm{T}_{1}\right)$; start of surgery $\left(\mathrm{T}_{2}\right) ; 30 \mathrm{~min}, 60 \mathrm{~min}, 90 \mathrm{~min}$, and 120 min after the start of surgery $\left(\mathrm{T}_{3}-\mathrm{T}_{6}\right)$; end of surgery $\left(\mathrm{T}_{7}\right)$; and 5 min after extubation $\left(\mathrm{T}_{8}\right)$. Arterial blood lactic acid was collected at $\mathrm{T}_{0}$ and $\mathrm{T}_{8}$.

Additionally, the duration of anesthesia and surgery, lengths of PACU and hospital stay, VAS pain score, and postoperative complications (including postoperative nausea and vomiting, hypotension, acute renal injury, wound infection, arrhythmia, and pneumonia) were recorded.

\section{Sample size and statistical analyses}

The primary outcome measure was the incidence of POD after spine surgery in the hospital. Based on the past data of our hospital, the incidence of POD was approximately $20.0 \%$ in patients who followed RF during spine surgery. According to the research of Zhang et al (Zhang et al. 2018), we assumed that the incidence of POD was approximately $6.67 \%$ in patients who followed GDT. A sample size of 97 patients in each group was calculated for a 0.05 difference (two-sided) with a power of $80 \%$. The sample size in the present study was calculated by using PASS 2008 (NCSS, LLC. Kaysville, Utah, USA) software. The final sample size in the present study was determined to be 106 patients per group when considering a $10 \%$ dropout rate and higher power. 
Statistical analyses were performed using SPSS version 21.0 (SPSS Inc., Chicago, IL, USA). The measurement data were tested for normal distribution with the Kolmogorov-Smirnov test and for homogeneity of variance with the Levene test. Normally distributed qualitative data are presented as the mean (standard deviation), and nonnormal distributions are expressed as the median (interquartile range, IQR). Categorical variables are expressed as numbers (\%). Categorical variables including sex, ASA classification, type of surgery, dependence on smoking, alcohol abuse, number of preoperative comorbidity, types of surgery, number of blood transfusion, and the incidence of postoperative complications were analyzed using the $\chi^{2}$ test or Fisher's exact tests for smaller events $(<5)$. Group comparisons of BMI and preoperative hemoglobin were assessed with Student's $t$ test (normally distributed qualitative data). Group comparisons of age, BMI, preoperative waiting time, preoperative HCT, length of PACU stay and hospital stay, postoperative VAS pain score, number of vertebrae involved in the surgery, anesthesia duration, surgery duration, volume of fluid infusion, amount of bleeding, volume of urine output, dosage of vasopressor, hypotensive events, and lactate acid were performed using the Mann-Whitney $U$ test (non-normally distributed qualitative data). Repeated measurement analysis of variance was used to analyze the intraoperative data of $\mathrm{rSO}_{2}, \mathrm{CI}, \mathrm{MAP}, \mathrm{HR}$, and BIS.

\section{Results}

A total of 260 patients with spinal surgery were screened in this study from May 2020 to November 2020. 228 patients met the inclusion criteria, and 220 patients were given consents and subsequently randomly assigned to the RF group or the GDT group. During the study period, 25 patients were excluded (18 patients who had a minimally invasive lumbar procedure, 3 patients who changed their fluid therapy due to severe hypotension, 2 patients who experienced severe complications during surgery, and 2 patients who did not complete the study). Ninety-seven patients in the RF group and 98 patients in the GDT group were included in the final analysis (Fig. 2).

\section{Patient characteristics and operative data}

No differences in age, gender, BMI, ASA, nicotine dependence, alcohol abuse, preoperative comorbidity, education years, preoperative hemoglobin, types of surgery, preoperative waiting time, number of patients using nonsteroidal anti-inflammatory drugs (NSAIDs), or number of vertebrae involved in the surgery were observed between the two groups (Table 1).

The intraoperative data of surgery and lactated Ringer's solution volume within $6 \mathrm{~h}$ after the operation are presented in Table 2. No differences in anesthesia duration, surgery duration, the length of PACU stay, patients received packed red blood cells, cell saver blood administered volume, and the lactated Ringer's solution

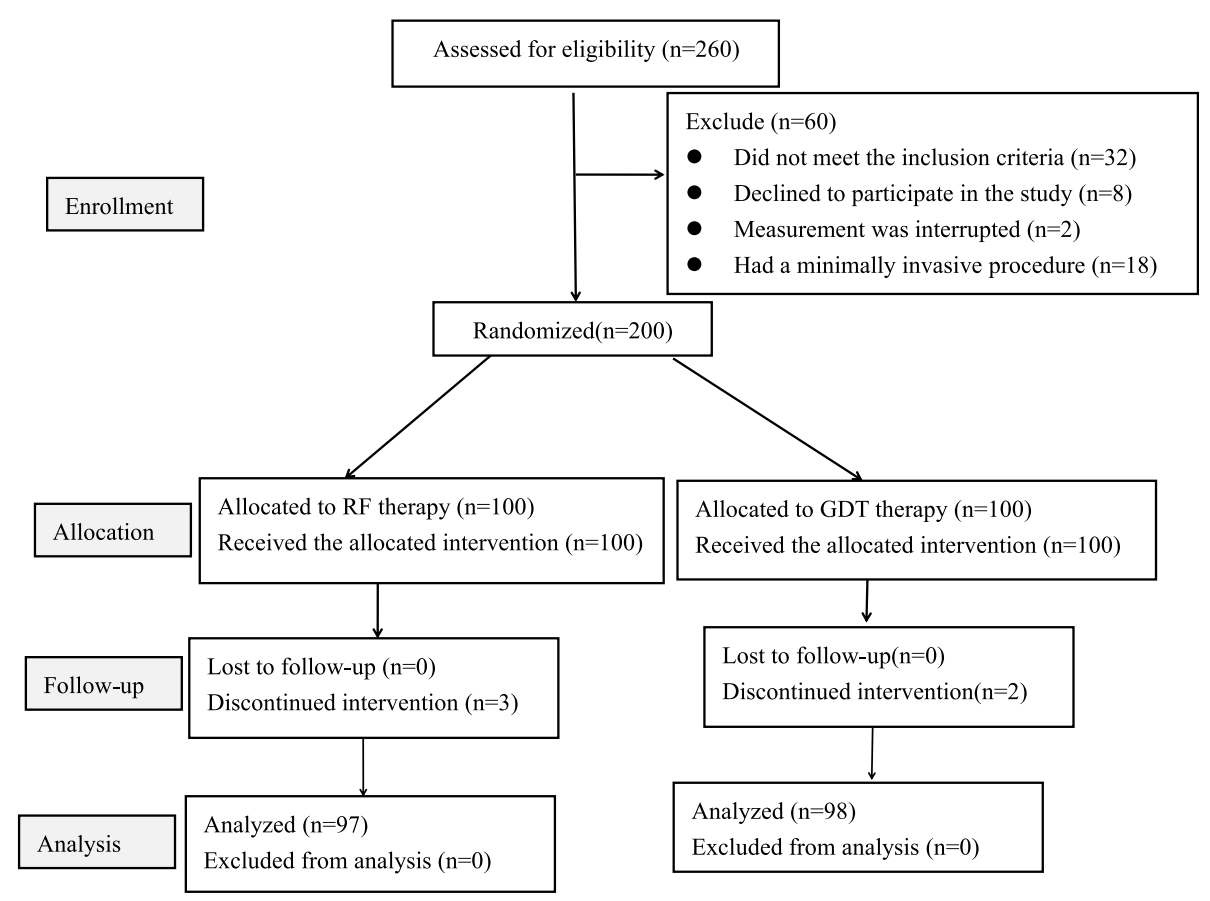

Fig. 2 Flow chart of the patients studied. RF restrictive fluid therapy, GDT goal-directed fluid therapy 
Table 1 Demographic characteristics of the study patients

\begin{tabular}{|c|c|c|c|}
\hline Characteristic & Group RF $(n=97)$ & Group GDT $(n=98)$ & $P$ value \\
\hline Age, med (IQR) & $60(55-68)$ & $58(56-66)$ & 0.929 \\
\hline Male, $n(\%)$ & $52(53.6)$ & $52(53.1)$ & 0.939 \\
\hline BMI $\left(\mathrm{kg} \cdot \mathrm{m}^{-2}\right)$, mean $(\mathrm{SD})$ & $23.54(3.40)$ & $23.80(2.75)$ & 0.547 \\
\hline \multicolumn{4}{|l|}{ ASA } \\
\hline I, n (\%) & $28(28.9)$ & $30(30.6)$ & 0.790 \\
\hline$\|, n(\%)$ & $69(71.1)$ & $68(69.4)$ & 0.790 \\
\hline \multicolumn{4}{|l|}{ Education, $n$ (\%) } \\
\hline Illiterate, $n$ (\%) & $30(30.9)$ & $30(30.6)$ & 0.718 \\
\hline $1-6$ years of education years, $n(\%)$ & $24(24.7)$ & $29(29.5)$ & 0.718 \\
\hline$\geq 7$ years of education years, $n(\%)$ & $43(44.3)$ & $39(39.7)$ & 0.718 \\
\hline Baseline MMSE, med (IQR) & $29(25-30)$ & $27(25-30)$ & 0.348 \\
\hline Dependence on smoking, $n$ (\%) & $19(19.5)$ & $18(18.3)$ & 0.828 \\
\hline Alcohol abuse, $n$ (\%) & $7(7.2)$ & $11(11.2)$ & 0.334 \\
\hline \multicolumn{4}{|l|}{ Comorbidity, n (\%) } \\
\hline Coronary heart disease, $n(\%)$ & $7(7.2)$ & $6(6.1)$ & 0.759 \\
\hline Hypertension, $n$ (\%) & $18(19.6)$ & $23(23.4)$ & 0.400 \\
\hline Diabetes mellitus, $n(\%)$ & $7(7.2)$ & $7(7.1)$ & 0.984 \\
\hline Hydrothorax, $n(\%)$ & $8(8.2)$ & $7(7.1)$ & 0.772 \\
\hline \multicolumn{4}{|l|}{ Type of surgery } \\
\hline Lumbar spine stenosis surgery, $n(\%)$ & $69(71.1)$ & $71(72.4)$ & 0.838 \\
\hline Thoracic spinal stenosis surgery, $n(\%)$ & $28(28.9)$ & $27(27.6)$ & 0.838 \\
\hline Number of vertebral levels ${ }^{c}$, med (IQR) & $2(2-3)$ & $2(2-3)$ & 0.797 \\
\hline Preoperative waiting time (d), med (IQR) & $6(5-8)$ & $6(5-8)$ & 0.418 \\
\hline Preoperative hemoglobin (mg/l), mean (SD) & $130.3(12.8)$ & $131.1(17.1)$ & 0.710 \\
\hline Preoperative hematocrit (\%), med (IQR) & $40(37-42)$ & $40(37-43)$ & 0.567 \\
\hline Number of patients using NSAIDs, $n(\%)$ & $11(11.3)$ & $12(14.3)$ & 0.538 \\
\hline
\end{tabular}

Med median, IQR interquartile range, SD standard deviation, ASA American Society of Anesthesiologists, BMI body mass index, med median, ' $\mathrm{Levels}$ were defined as the number of vertebrae involved in the surgery, NASIDs nonsteroidal anti-inflammatory drugs

volume within $6 \mathrm{~h}$ after operation were found between the two groups. Compared with group RF, group GDT had a higher volume of intraoperative lactated Ringer's solution [1500 (1128 to 1775$) \mathrm{mL}$ versus 1000 (765 to 1300) $\mathrm{mL}, P<0.001)$ and total intraoperative fluid infusion [1700 (1396 to 2200) $\mathrm{mL}$ versus 1280 (961 to 1611) $\mathrm{mL}, P<0.001]$, but there was no difference in HES infused volume and amount of bleeding between the two groups. Patients in group RF were more likely than those in group GDT to have lower urine output [300 (200 to 530) $\mathrm{mL}$ versus 398 (288 to 600$) \mathrm{mL}, P=0.012$ ], receive more vasopressor support $(P=0.015)$, experience more hypotensive events $(P<0.001)$, and prolong the length of hospital stay [17.0 (14 to 20 ) days versus 14.5 (13 to 17.0) days, $P=0.001$ ] (Table 2 ).

\section{Primary endpoint}

The overall incidence of POD was approximately $8.2 \%$ in the first 3 days after spine surgery in middle- and old- aged patients. Postoperative delirium occurred in 12 (12.4\%) of 97 patients given restrictive fluid therapy and in $4(4.1 \%)$ of 98 patients given GDT (odds ratio [OR] 0.301, 95\% CI 0.094-0.970; $P=0.035$ ) during 3-day follow-up. Patients in group GDT showed a lower prevalence of POD on postoperative days 1-2 than patients in group RF (day 1: $10.3 \%$ versus $3.1 \%, P=0.042$; day 2 : $9.3 \%$ versus $2.0 \%, P=0.029$ ). There was no significant difference in the prevalence of POD on the third day between the group RF and the group GDT (Table 3).

\section{Secondary endpoints and postoperative characteristics}

Compared with $\mathrm{T}_{0}, \mathrm{rSO}_{2}$ in group $\mathrm{RF}$ was increased at $\mathrm{T}_{2}-\mathrm{T}_{4}$ but decreased at $\mathrm{T}_{5}-\mathrm{T}_{8}$, while compared with $\mathrm{T}_{0}$, $\mathrm{rSO}_{2}$ in group GDT was increased at $\mathrm{T}_{1}-\mathrm{T}_{8}(P<0.05)$. Compared with $\mathrm{T}_{0}, \mathrm{MAP}, \mathrm{CI}$, and BIS in both groups were decreased at $\mathrm{T}_{1}-\mathrm{T}_{8}(P<0.05)$. Compared with $\mathrm{T}_{0}$, $\mathrm{HR}$ in both groups was decreased at $\mathrm{T}_{1}-\mathrm{T}_{7}$ but increased at $\mathrm{T}_{8}(P<0.05)$. Compared with group RF, MAP 
Table 2 Surgical data with outcomes

\begin{tabular}{|c|c|c|c|}
\hline & $\begin{array}{l}\text { Group } \\
\operatorname{RF}(n=97)\end{array}$ & $\begin{array}{l}\text { Group } \\
\text { GDT }(n=98)\end{array}$ & $P$ value \\
\hline Anesthesia duration (min), med (IQR) & $195(172-232)$ & $205(163-240)$ & 0.918 \\
\hline Surgery duration (min), med (IQR) & $167(141-203)$ & $176(137-218)$ & 0.963 \\
\hline Total intraoperative fluid volume & $1280(961-1611)$ & $1700(1396-2200)$ & $<0.001$ \\
\hline Intraoperative lactated Ringer's solution volume $(\mathrm{mL})$, med (IQR) & $1000(765-1300)$ & $1500(1128-1775)$ & $<0.001$ \\
\hline Intraoperative HES (mL), med (IQR) & $300(200-440)$ & $300(250-500)$ & 0.312 \\
\hline Intraoperative hypotensive event, med (IQR) & $1(0-2)$ & $0(0-1)$ & $<0.001$ \\
\hline Intraoperative ephedrine dose (mg), med (IQR) & $6(0-12)$ & $0(0-6)$ & 0.015 \\
\hline Intraoperative urine output (mL), med (IQR) & $300(200-530)$ & $398(288-600)$ & 0.012 \\
\hline \multicolumn{4}{|l|}{ Intraoperative blood transfusion } \\
\hline Patients receiving packed RBCs, n (\%) & $8(8.2)$ & $6(6.1)$ & 0.565 \\
\hline Cell saver blood (mL), med (IQR) & $0(0-125)$ & $0(0-134)$ & 0.661 \\
\hline Intraoperative estimated blood loss (mL), med (IQR) & $270(200-320)$ & $268(200-351)$ & 0.520 \\
\hline Length of PACU stay (min), med (IQR) & $83(65-113)$ & $78(64-98)$ & 0.407 \\
\hline Length of hospital stay (days), med (IQR) & $17.0(14.0-20.0)$ & $14.5(13.0-17.0)$ & $<0.001$ \\
\hline Lactated Ringer's solution volume within $6 \mathrm{~h}$ after operation $(\mathrm{mL})$, med (IQR) & $372(339-435)$ & $390(342-450)$ & 0.275 \\
\hline
\end{tabular}

Anesthesia duration refers to the time from the beginning of anesthesia to the end of anesthesia. Surgery duration refers to the time from the beginning of surgery to the end of surgery

$P A C U$ postanesthesia care unit, $R B C$ red blood cell

and $\mathrm{rSO}_{2}$ were increased at $\mathrm{T}_{5}-\mathrm{T}_{8}$ in group GDT. Compared with group RF, CI and $\mathrm{HR}$ were increased at $\mathrm{T}_{6}-$ $\mathrm{T}_{8}$ in group GDT $(P<0.05)$. There was no significance in BIS values between group RF and group GDT $(P>$ 0.05) (Fig. 3).

The intraoperative change in lactate (postoperative compared to preoperative) in the RF group ranged from -0.5 to $1.5 \mathrm{mmol} / \mathrm{L}$ with a median of 0.2 (interquartile range 0.0 to 0.3 ), and in the GDT group, this change ranged from -1.2 to $0.9 \mathrm{mmol} / \mathrm{L}$ with a median of -0.1 (interquartile range -0.3 to 0.0 ). Although there was a statistical significance in postoperative lactic acid level between group RF and group GDT $(P<0.05$, Table 4$)$, it had a lower power for clinical significance.

Postoperative VAS pain scores and postoperative complications, including postoperative nausea and vomiting, hypotension, acute renal injury, wound infection, arrhythmia, and pneumonia (Table 4), were compared between the RF group and the GDT group. Compared with group RF, the incidence of hypotension showed an increasing trend in the restrictive group (5 versus $1, P=$
0.118), though this trend was not clinically significant (Table 4).

\section{Discussion}

This prospective randomized study found that the POD incidence for middle- and old-aged patients in the first 3 days after spine surgery was $8.2 \%$. GDT compared with $\mathrm{RF}$ was found to be associated with a reduced of incidence of POD in the first 3 days after surgery and a reduced prevalence of POD on postoperative days 1-2.

In our study, the incidence of POD in the RF group was $12.4 \%$, relatively lower than the historical incidence of POD at our institution. The reasons that led to the low delirium incidence in the current patient population may include the following. Firstly, none of the patients received any sedative medications before the induction of anesthesia, especially benzodiazepines often used as preoperative routine medication in our institution, which may increase the incidence of POD (Poeran et al. 2020). Secondly, our study excluded patients with visual, auditory, or language communication disorders, and those

Table 3 Daily prevalence of postoperative delirium

\begin{tabular}{llll}
\hline & Group RF $(\boldsymbol{n}=\mathbf{9 7})$ & Group GDT $(\boldsymbol{n}=\mathbf{9 8})$ & $\boldsymbol{P}$ value \\
\hline POD & & & $3(3.1)$ \\
1 day postoperative, $n(\%)$ & $10(10.3)$ & $2(2.0)$ & 0.042 \\
2 days postoperative, $n(\%)$ & $9(9.3)$ & $1(1.0)$ & 0.029 \\
3 days postoperative, $n(\%)$ & $3(3.1)$ & & 0.369 \\
\hline POD postoperative delirium & &
\end{tabular}



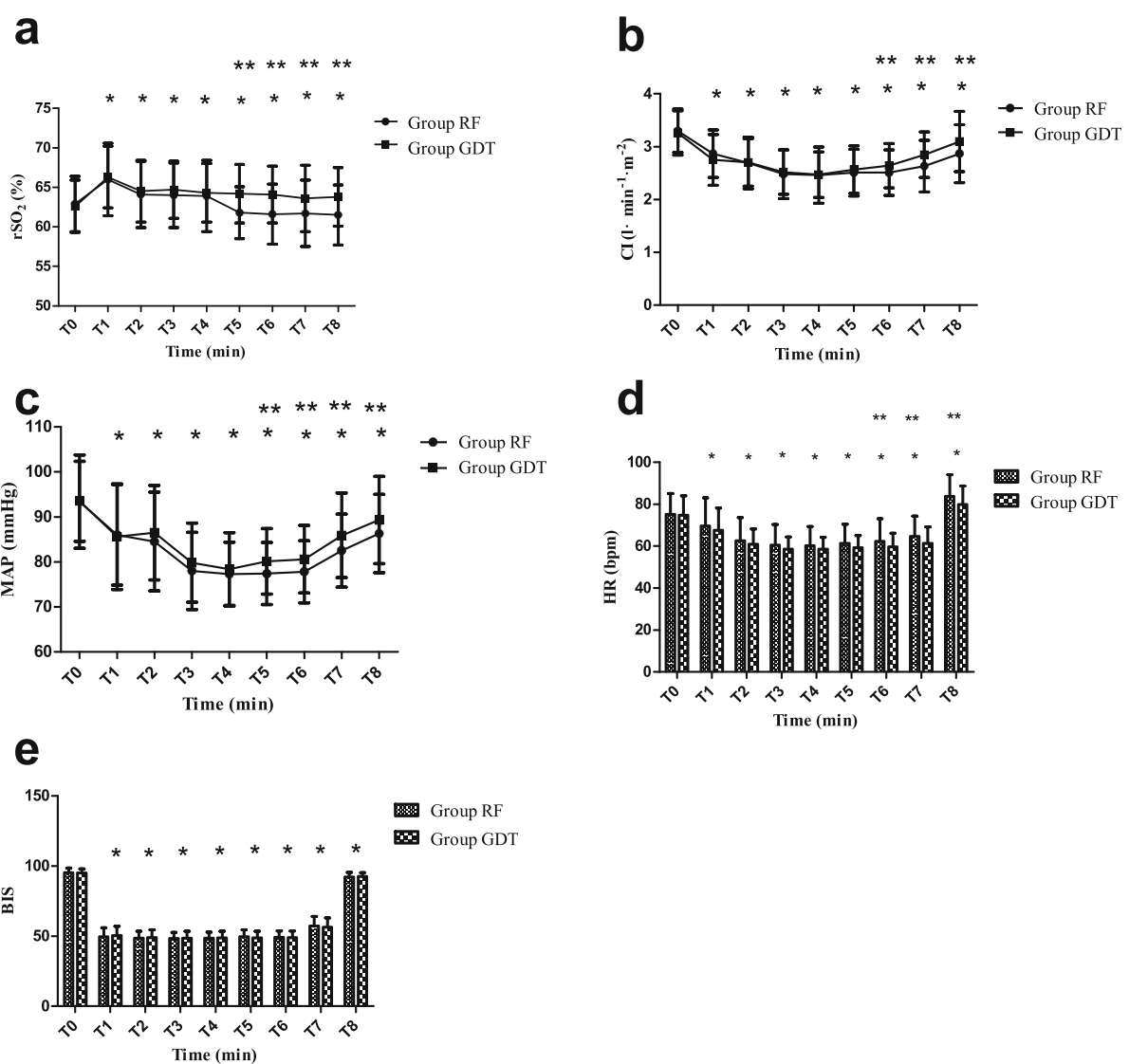

Fig. 3 Continuous variables are presented as mean (standard deviation). Compared with $T_{0}, r \mathrm{O}_{2}$ in group RF was increased at $T_{2}-T_{4}$ but decreased at $T_{5}-T_{8}$, while compared with $T_{0}, r \mathrm{rO}_{2}$ in group GDT was increased at $T_{1}-T_{8}$. Compared with $T_{0}, M A P, C l$, and BIS in both groups were decreased at $T_{1}-$ $\mathrm{T}_{8}$. Compared with $\mathrm{T}_{0}, \mathrm{HR}$ in both groups was decreased at $\mathrm{T}_{1}-\mathrm{T}_{7}$ but increased at $\mathrm{T}_{8}\left({ }^{*} P<0.05\right)$. Compared with group $\mathrm{RF}$, intraoperative $\mathrm{rSO}_{2}$ and MAP values were increased at $T_{5}-T_{8}$ in group GDT $\left({ }^{* *} P<0.05\right)(\mathbf{a}, \mathbf{c})$; compared with group $R F$, intraoperative $C l$ and $H R$ values were increased at $T_{6}-T_{8}$ in group GDT ( $\left.{ }^{* *} P<0.05\right)(\mathbf{b}, \mathbf{d}) . T_{0}: 5$ min before the induction of anesthesia; $T_{1}: 5$ min after induction of anesthesia; $T_{2}:$ start of surgery; $T_{3}: 30$ min after the start of surgery; $T_{4}: 60$ min after the start of surgery; $T_{5}: 90$ min after the start of surgery; $T_{6}: 120$ min after the start of surgery; $T_{7}:$ end of surgery; $T_{8}$ : 5 min after extubation. MAP mean arterial pressure, $\mathrm{rSO}_{2}$ regional cerebral oxygen saturation, $\mathrm{HR}$ heart rate, $\mathrm{Cl}$ cardiac index, $\mathrm{BIS}$ bispectral index

with any significant comorbid disease. These patients were at a great increased risk of delirium (Inouye et al. 2014; Jung et al. 2018; Aldecoa et al. 2017).

Spinal surgery often needs to be performed in the prone position, and dramatic changes in position will lead to hemodynamic instability (Bacchin et al. 2016). Recently, studies have shown that GDT can provide stable hemodynamics, effectively optimize the relationship between tissue perfusion and volume loads, and improve postoperative outcomes (Cannesson 2010; Tapia et al. 2021; Bacchin et al. 2016; Zhang et al. 2018). To our knowledge, this study is one of the few studies to directly compare the effects of intraoperative RF with PPV-directed fluid therapy on the incidence of POD in patients undergoing spinal surgery. Our results suggest that PPV-directed fluid therapy results in a reduced incidence of POD and a shorter length of hospital stay than $\mathrm{RF}$. However, the incidence of other postoperative complications was similar between the two groups.
The accuracy and early recognition of the intravascular volume status are essential to prevent both hypoperfusion due to volume depletion and fluid overload due to an unnecessary infusion (Zhang et al. 2012), which may promote the occurrence of POD. Therefore, appropriate hemodynamic monitoring is necessary for intraoperative fluid management. A simple, affordable, and reliable method to achieve this goal would be appropriate for the routine intraoperative application. The PPV based on blood pressure waveforms detected with the CNAP system has been shown to be reliable (Jeleazcov et al. 2010; Biais et al. 2017). This type of PPV monitoring is not associated with additional costs or complications other than arterial catheterization. Benes et al. (Benes et al. 2015) demonstrated that intraoperative PPV-guided fluid therapy during total knee and hip replacement surgery improved postoperative outcomes. PPV has also been validated in the prone position: a study from Yang et al. (Yang et al. 2013) demonstrated that PPV can reliably 
Table 4 Preoperative and postoperative blood tests and postoperative complications

\begin{tabular}{|c|c|c|c|}
\hline & Group RF $(n=97)$ & Group GDT $(n=98)$ & $P$ value \\
\hline \multicolumn{4}{|l|}{ VAS pain score, med (IQR) } \\
\hline $24 \mathrm{~h}$ postoperatively, med (IQR) & $3(2-4)$ & $3(2-4)$ & 0.753 \\
\hline $48 \mathrm{~h}$ postoperatively, med (IQR) & $2(2-3)$ & $2(2-3)$ & 0.854 \\
\hline $72 \mathrm{~h}$ postoperatively, med (IQR) & $2(1-2)$ & $2(1-3)$ & 0.855 \\
\hline Preoperative creatinine $(\mu \mathrm{mol} / \mathrm{l})$, med (IQR) & $57(49-68)$ & $59(48-73)$ & 0.672 \\
\hline Postoperative creatinine $(\mu \mathrm{mol} / \mathrm{l})$, med (IQR) & $57(49-78)$ & $56(44-66)$ & 0.074 \\
\hline Preoperative lactic acid, med (IQR) & $1.2(0.7-1.6)$ & $1.2(0.9-1.7)$ & 0.393 \\
\hline Postoperative lactic acid, med (IQR) & $1.3(1.0-1.8)$ & $1.2(0.8-1.4)$ & 0.001 \\
\hline Change of lactic acid, med (IQR) & $0.2(0.0-0.3)$ & $-0.1(-0.3-0.0)$ & 0.000 \\
\hline \multicolumn{4}{|l|}{ Complications, $n$ (\%) } \\
\hline PONV, $n(\%)$ & $13(13.4)$ & $16(16.3)$ & 0.566 \\
\hline Hypotension, $n(\%)$ & $5(5.2)$ & $1(1.0)$ & 0.118 \\
\hline Acute renal injury, $n(\%)$ & $4(4.1)$ & $1(1.0)$ & 0.212 \\
\hline Wound infection, $n$ (\%) & $2(2.0)$ & $0(0.0)$ & 0.246 \\
\hline Arrhythmia, $n(\%)$ & $3(3.1)$ & $1(1.0)$ & 0.369 \\
\hline Pneumonia, $n(\%)$ & $1(1.0)$ & $1(1.0)$ & 1.000 \\
\hline
\end{tabular}

VAS visual analog scale, PONV postoperative nausea and vomiting, Change of lactic acid postoperative lactic acid-preoperative lactic acid

predict fluid responsiveness in the prone position, albeit with a lower threshold than in supine position (15\% vs 14\%). According to Yang's (Yang et al. 2013) study, we used a PPV $>14 \%$ as a trigger for intraoperative administration of a fluid bolus to target volume optimization in this study.

Many studies have investigated the effects of the amount of intraoperative fluid administration on perioperative outcomes. Studies have demonstrated that fluid overload increases the incidence of perioperative complications in spinal surgery, such as POD (Brown et al. 2016) and pulmonary complications (Siemionow et al. 2012a, b), whereas RF yields better outcomes, including fewer postoperative complications and a shorter length of hospital stay (Brandstrup et al. 2003; Hart et al. 2013; Shin et al. 2018). A study of cervical decompression and fusion across the cervicothoracic junction reported that intraoperative restriction of IV fluid while maintaining adequate blood pressure reduces airway complications in this patient population (Hart et al. 2013). Additionally, RF, including avoidance of synthetic colloids to reduce dilution and colloid-induced coagulopathy and increased bleeding, is a crucial element of patient blood-management strategies, while patient blood management has been reported to reduce the need for red blood cell (RBC) transfusion in idiopathic scoliosis posterior spinal surgery (Ohrt-Nissen et al. 2017). However, intraoperative fluid restriction is associated with frequent episodes of intraoperative hypotension, which is a major determinant of postoperative organ dysfunction (Zhang et al. 2012), and hypotension may be a risk factor of POD development (Patti et al. 2011; Maheshwari et al. 2020). In addition, several studies have examined the effects of intraoperative GDT on perioperative outcomes. Researchers have demonstrated that GDT reduces the incidence of POD and the duration of hypotensive episodes in major spine surgery (Picard et al. 2016; Zhang et al. 2018). A metaanalysis including six trials with a total of 562 participants found that based on very low-certainty evidence, RF may increase the risk of all-cause mortality compared to GDT, but the evidence is very uncertain (Wrzosek et al. 2019). Based on very low-certainty evidence, whether GDT is superior to a restrictive fluid strategy in major spinal surgery remains uncertain. In our study, patients who were treated using GDT received greater amounts of fluid than patients who were treated with RF. Additionally, MAP at $\mathrm{T}_{5}-\mathrm{T}_{8}$ and $\mathrm{CI}$ at $\mathrm{T}_{6}-\mathrm{T}_{8}$ in the GDT group were higher than those in the RF group, and intraoperative hypotensive events were lower in the GDT group than in the RF group, indicating that patients undergoing major spinal surgery may benefit from GDT (compared with RF), with a reduction in intraoperative hypotensive events and the incidence of POD.

Some studies have suggested that intraoperative hemodynamic fluctuation may result in transient cerebral hypoperfusion (Hirsch et al. 2015; van Waes et al. 2016), which may promote the incidence of POD. Previous studies found that intraoperative hypotension was significantly associated with developing POD (Patti et al. 2011; Maheshwari et al. 2020). Significant intraoperative hypotension often necessitates the use of vasoactive 
medications and several studies have found that POD was associated with higher intraoperative vasopressor usage (Rudiger et al. 2016; Neerland et al. 2017). In our study, patients in group GDT were more likely than those in group RF to maintain more stable perioperative hemodynamics, experience lower intraoperative hypotensive events, receive more vasoactive drug, and have a lower incidence of POD, indicating that GDT may maintain hemodynamic stability and avoid intraoperative hypotension to prevent cerebral hypoperfusion, thereby reducing the incidence of POD.

Recently, a meta-analysis suggested that early GDT improves tissue perfusion and oxygenation in high-risk patients undergoing major abdominal and orthopedic surgery (Giglio et al. 2019). Accumulating evidence suggests that $\mathrm{rSO}_{2}$ reflects the overall cerebral tissue oxygen supply/demand (Fischer and Silvay 2010; Rescoe et al. 2017), and higher $\mathrm{rSO}_{2}$ desaturation is significantly associated with POD in certain types of surgery (Green and Kunst 2017; Wang et al. 2019). In our study, we used $\mathrm{rSO}_{2}$ to reflect the effect of intraoperative fluid therapy on POD. In this study, there was no statistically significant difference in preoperative hemoglobin content between the two groups, and the inhaled oxygen concentration was controlled at 50\% during surgery. Perioperative $\mathrm{P}_{\mathrm{ET}} \mathrm{CO}_{2}$ was controlled at $35-45 \mathrm{mmHg}$, and the intraoperative body temperature was maintained at a constant level to eliminate interference by other factors in the $\mathrm{rSO}_{2}$ value. In our study, $\mathrm{rSO}_{2}$ in the GDT group was higher than that in the RF group after $90 \mathrm{~min}$ of surgery, and the incidence of POD was lower than that in the RF group, indicating that compared with RF, GDT can improve $\mathrm{rSO}_{2}$ in spinal surgery, which may be helpful to reduce the incidence of POD.

There are many factors affecting POD, such as age, BMI, ASA score, and postoperative pain (Radinovic et al. 2019). In this study, there were no statistically significant differences in age, ASA classification, BMI, or postoperative pain, which ensures the comparability of the two groups. A previous study also suggested that hydroxyethyl starch administration was related to early POD (Jung et al. 2018). In this study, there were no statistically significant differences in hydroxyethyl starch administration between the two groups, which endure the comparability of the two fluid therapies. The metaanalysis reported that BIS at different depths may influence POD (Bocskai et al. 2020). In this study, there were no statistically significant differences in BIS values.

Nonetheless, there were a few limitations in this study. Firstly, we excluded seven patients (3 patients changed their fluid therapy due to severe hypotension in the RF group, 2 patients who experienced severe complications during surgery in the GDT group, and 1 patient in each group who did not complete the study) in analysis.
Secondly, GDT was only performed during the intraoperative period, the application time was short, and there was no long-term follow-up. Thirdly, only RF and GDT were compared, and they were not compared with liberal fluid therapy. Fourthly, there was a lack of blood indicators to monitor POD, such as S100 $\beta$, IL-6, and IGFI. Furthermore, considering that this study was a small sample size, single-center, and patients with strict and extensive inclusion and exclusion criteria, the extrapolation of our study to other populations was limited. Thus, further prospective studies with larger populations and longer follow-up times are required to compare the effects of RF, traditional fluid therapy, and GDT on delirium.

\section{Conclusion}

In summary, GDT can reduce the incidence of POD and shorten the length of hospital stay in middle- and oldaged patients undergoing spine surgery, and it may be related to maintain the stability of perioperative hemodynamics and increased cerebral oxygen supply.

\section{Abbreviations}

POD: Postoperative delirium; GDT: Goal-directed fluid therapy; RF: Restrictive fluid therapy; CNAP: Continuous noninvasive arterial pressure; PPV: Pulse pressure variation; $\mathrm{rSO}_{2}$ : Regional cerebral oxygen saturation; MAP: Mean arterial pressure; HR: Heart rate; Cl: Cardiac index; VAS: Visual analog scale; SV: Stroke volume; $\mathrm{P}_{\mathrm{ET}} \mathrm{CO}_{2}$ : End-tidal pressure of carbon dioxide; IV: Intravenous; PACU: Postanesthesia care unit; HES: Hydroxyethyl starch 130/0.4 sodium chloride injection; CAM-CR: Confusion Assessment MethodChinese Reversion Scale; IQR: Interquartile range; BMI: Body mass index; ASA: American Society of Anesthesiologists; PONV: Postoperative nausea and vomiting; RBC: Red blood cell

\section{Acknowledgements}

We acknowledge that the first and second authors made equal contributions to writing and finalizing this manuscript.

\section{Authors' contributions}

DDW: Conceptualization, data curation, funding acquisition, investigation, methodology, project administration, resources, software, and writing-original draft. YL: Methodology, resources, funding acquisition, and validation. XWH: Conceptualization, data curation, formal analysis, methodology, project administration, resources, supervision, and writing - review and editing. MCZ: Formal analysis and resources. XX: Funding acquisition, investigation, and visualization. JT: Funding acquisition and investigation. The authors read and approved the final manuscript.

\section{Funding}

This research did not receive any specific grant from funding agencies in the public, commercial, or not-for-profit sectors.

\section{Availability of data and materials}

The datasets used and/or analyzed during the current study are available from the corresponding author on reasonable request.

\section{Declarations}

Ethics approval and consent to participate

This study was reviewed and approved by the Ethics Committee for Clinical Trials of the Second Affiliated Hospital of Anhui Medical University, Hefei, China [approval no.: PJ-YX2019-052(F2)]. All patients/participants provided written informed consent. 


\section{Consent for publication}

Not applicable.

\section{Competing interests}

The authors declare that no grants/funding were involved in supporting this manuscript.

\section{Received: 22 February 2021 Accepted: 10 September 2021}

Published online: 15 December 2021

\section{References}

Aitken SJ, Blyth FM, Naganathan V. Incidence, prognostic factors and impact of postoperative delirium after major vascular surgery: a meta-analysis and systematic review. Vasc Med. 2017;22(5):387-97. https://doi.org/10.1177/13 $58863 \times 17721639$.

Aldecoa C, Bettelli G, Bilotta F, Sanders RD, Audisio R, Borozdina A, et al. European Society of Anaesthesiology evidence-based and consensus-based guideline on postoperative delirium. Eur J Anaesthesiol. 2017;34(4):192-214. https://doi.org/10.1097/EJA.0000000000000594.

American Society of Psychiatrists.DSM-5 Criteria for Delirium. The Diagnostic and Statistical Manual of Mental Disorders (DSM-5). Washington, DC: American Society of Psychiatrists; 2013.

Bacchin MR, Ceria CM, Giannone S, Ghisi D, Stagni G, Greggi T, et al. Goal-directed fluid therapy based on stroke volume variation in patients undergoing major spine surgery in the prone position: a cohort study. Spine (Phila Pa 1976). 2016; 41:E1131-7. https://doi.org/10.1097/BRS.0000000000001601.

Benes J, Haidingerova L, Pouska J, Stepanik J, Stenglova A, Zatloukal J, et al. Fluid management guided by a continuous non-invasive arterial pressure device is associated with decreased postoperative morbidity after total knee and hip replacement. BMC Anesthesiol. 2015;15(1):148. https://doi.org/10.1186/s12 871-015-0131-8.

Biais M, Stecken L, Martin A, Roullet S, Quinart A, Sztark F. Automated, continuous and non-invasive assessment of pulse pressure variations using CNAP ${ }^{\oplus}$ system. J Clin Monit Comput. 2017;31(4):685-92. https://doi.org/10.1007/s1 0877-016-9899-4

Bocskai T, Kovács M, Szakács Z, Gede N, Hegyi P, Varga G, et al. Is the bispectral index monitoring protective against postoperative cognitive decline? A systematic review with meta-analysis. PLoS One. 2020;15(2):e0229018. https:// doi.org/10.1371/journal.pone.0229018.

Brandstrup B, Tønnesen H, Beier-Holgersen R, Hjortsø E, Ørding H, Lindorff-Larsen $\mathrm{K}$, et al. Effects of intravenous fluid restriction on postoperative complications: comparison of two perioperative fluid regimens: a randomized assessor-blinded multicenter trial. Ann Surg. 2003;238(5):641-8. https://doi.org/10.1097/01.sla.0000094387.50865.23.

Brown CH, LaFlam A, Max L, Wyrobek J, Neufeld KJ, Kebaish KM, et al. Delirium after spine surgery in older adults: incidence, risk factors, and outcomes. J Am Geriatr Soc. 2016;64(10):2101-8. https://doi.org/10.1111/jgs.14434.

Cannesson M. Arterial pressure variation and goal-directed fluid therapy. J Cardiothorac Vasc Anesth. 2010;24(3):487-97. https://doi.org/10.1053/j.jvca.2 009.10.008.

Cascella M, Muzio MR, Bimonte S, Cuomo A, Jakobsson JG. Postoperative delirium and postoperative cognitive dysfunction: updates in pathophysiology, potential translational approaches to clinical practice and further research perspectives. Minerva Anestesiol. 2018;84(2):246-60. https:// doi.org/10.23736/S0375-9393.17.12146-2.

Coeckelenbergh S, Delaporte A, Ghoundiwal D, Bidgoli J, Fils JF, Schmartz D, et al. Pleth variability index versus pulse pressure variation for intraoperative goal-directed fluid therapy in patients undergoing low-to-moderate risk abdominal surgery: a randomized controlled trial. BMC Anesthesiol. 2019; 19(1):34. https://doi.org/10.1186/s12871-019-0707-9.

Fischer GW, Silvay G. Cerebral oximetry in cardiac and major vascular surgery. HSR Proc Intensive Care Cardiovasc Anesth. 2010;2:249-56.

Giglio M, Dalfino L, Puntillo F, Brienza N. Hemodynamic goal-directed therapy and postoperative kidney injury: an updated meta-analysis with trial sequential analysis. Crit Care. 2019;23(1):232. https://doi.org/10.1186/s13054019-2516-4

Green DW, Kunst G. Cerebral oximetry and its role in adult cardiac, non-cardiac surgery and resuscitation from cardiac arrest. Anaesthesia. 2017;72(Suppl 1): 48-57. https://doi.org/10.1111/anae.13740.

Guo Y, Zhang Y, Jia P, Wang W, Zhou Q, Sun L, et al. Preoperative serum metabolites are associated with postoperative delirium in elderly hip-fracture patients. J Gerontol A Biol Sci Med Sci. 2017;72(12):1689-96. https://doi.org/1 0.1093/gerona/glx001.

Hart RA, Dupaix JP, Rusa R, Kane MS, Volpi JD. Reduction of airway complications with fluid management protocol in patients undergoing cervical decompression and fusion across the cervicothoracic junction. Spine (Phila Pa 1976). 2013;38:E1135-40. https://doi.org/10.1097/BRS.0b013e31829914ed.

Hasanin A, Zanata T, Osman S, Abdelwahab Y, Samer R, Mahmoud M, et al. Pulse pressure variation-guided fluid therapy during supratentorial brain tumour excision: a randomized controlled trial. Open Access Maced J Med Sci. 2019; 7(15):2474-9. https://doi.org/10.3889/oamjms.2019.682.

Hirsch J, DePalma G, Tsai TT, Sands LP, Leung JM. Impact of intraoperative hypotension and blood pressure fluctuations on early postoperative delirium after non-cardiac surgery. Br J Anaesth. 2015;115(3):418-26. https://doi.org/1 $0.1093 / \mathrm{bja} / \mathrm{aeu} 458$.

Hughes CG, Patel MB, Pandharipande PP. Pathophysiology of acute brain dysfunction: what's the cause of all this confusion. Curr Opin Crit Care. 2012; 18(5):518-26. https://doi.org/10.1097/MCC.0b013e328357effa.

Inouye SK, Westendorp RG, Saczynski JS. Delirium in elderly people. Lancet. 2014; 383(9920):911-22. https://doi.org/10.1016/S0140-6736(13)60688-1.

Jeleazcov C, Krajinovic L, Münster T, Birkholz T, Fried R, Schüttler J, et al. Precision and accuracy of a new device (CNAPTM) for continuous non-invasive arterial pressure monitoring: assessment during general anaesthesia. Br J Anaesth. 2010;105(3):264-72. https://doi.org/10.1093/bja/aeq143.

Jiang X, Chen D, Lou Y, Li Z. Risk factors for postoperative delirium after spine surgery in middle- and old-aged patients. Aging Clin Exp Res. 2017;29(5): 1039-44. https://doi.org/10.1007/s40520-016-0640-4.

Juan L, Yizhuang Z, Feng F, Yuying T. Reversion of CAM for assisting the evaluation and diagnosis of delirium. J Clin Psychol Med. 2003;13:147-9. https://doi.org/10.3969/j.issn.1005-3220.2003.03.009.

Jung DM, Ahn HJ, Yang M, Kim JA, Kim DK, Lee SM, et al. Hydroxyethyl starch is associated with early postoperative delirium in patients undergoing esophagectomy. J Thorac Cardiovasc Surg. 2018;155(3):1333-43. https://doi. org/10.1016/j.jtcvs.2017.10.077.

Li H, Jia J, Yang Z. Mini-mental state examination in elderly chinese: a population-based normative study. J Alzheimers Dis. 2016;53(2):487-96. https://doi.org/10.3233/JAD-160119.

Maheshwari K, Ahuja S, Khanna AK, Mao G, Perez-Protto S, Farag E, et al. Association between perioperative hypotension and delirium in postoperative critically ill patients: a retrospective cohort analysis. Anesthesia and analgesia. 2020;130(3):636-43. https://doi.org/10.1213/ANE. 0000000000004517.

Mailhot T, Cossette S, Lambert J, Beaubien-Souligny W, Cournoyer A, O'Meara E, et al. Delirium after cardiac surgery and cumulative fluid balance: a casecontrol cohort study. J Cardiothorac Vasc Anesth. 2019;33(1):93-101. https:// doi.org/10.1053/j.jvca.2018.07.012

Makaryus R, Miller TE, Gan TJ. Current concepts of fluid management in enhanced recovery pathways. Br J Anaesth. 2018;120(2):376-83. https://doi. org/10.1016/j.bja.2017.10.011.

Miller D, Lewis SR, Pritchard MW, Schofield-Robinson OJ, Shelton CL, Alderson P, et al. Intravenous versus inhalational maintenance of anaesthesia for postoperative cognitive outcomes in elderly people undergoing non-cardiac surgery. Cochrane Database Syst Rev. 2018;8(10):CD012317. https://doi.org/1 0.1002/14651858.CD012317.pub2.

Myles PS, Mcllroy DR, Bellomo R, Wallace S. Importance of intraoperative oliguria during major abdominal surgery: findings of the Restrictive versus Liberal Fluid Therapy in Major Abdominal Surgery trial. Br J Anaesth. 2019;122(6): 726-33. https://doi.org/10.1016/j.bja.2019.01.010.

Neerland BE, Krogseth M, Juliebø V, Hylen Ranhoff A, Engedal K, Frihagen F, et al. Perioperative hemodynamics and risk for delirium and new onset dementia in hip fracture patients; a prospective follow-up study. PLoS One. 2017;12(7): e0180641. https://doi.org/10.1371/journal.pone.0180641.

Ohrt-Nissen S, Bukhari N, Dragsted C, Gehrchen M, Johansson PI, Dirks J, et al. Blood transfusion in the surgical treatment of adolescent idiopathic scoliosisa single-center experience of patient blood management in 210 cases. Transfusion. 2017;57(7):1808-17. https://doi.org/10.1111/trf.14137.

Patti R, Saitta M, Cusumano G, Termine G, Di Vita G. Risk factors for postoperative delirium after colorectal surgery for carcinoma. European journal of oncology nursing : the official journal of European Oncology Nursing Society. 2011; 15(5):519-23. https://doi.org/10.1016/j.ejon.2011.01.004.

Picard J, Bedague D, Bouzat P, Ollinet C, Albaladejo P, Bosson JL, et al. Oesophageal Doppler to optimize intraoperative haemodynamics during 
prone position. A randomized controlled trial. Anaesth Crit Care Pain Med. 2016;35(4):255-60. https://doi.org/10.1016/.j.accpm.2015.12.011.

Poeran J, Cozowicz C, Zubizarreta N, Weinstein SM, Deiner SG, Leipzig RM, et al. Modifiable factors associated with postoperative delirium after hip fracture repair: an age-stratified retrospective cohort study. Eur J Anaesthesiol. 2020; 37:649-58. https://doi.org/10.1097/EJA.0000000000001197.

Radinovic K, Markovic DL, Milan Z, Cirkovic A, Baralic M, Bumbasirevic V. Impact of intraoperative blood pressure, blood pressure fluctuation, and pulse pressure on postoperative delirium in elderly patients with hip fracture: a prospective cohort study. Injury. 2019;50(9):1558-64. https://doi.org/10.1016/j. injury.2019.06.026

Rescoe E, Tang X, Perry DA, Sleeper LA, DiNardo JA, Kussman BD, et al. Cerebral near-infrared spectroscopy insensitively detects low cerebral venous oxygen saturations after stage 1 palliation. J Thorac Cardiovasc Surg. 2017;154(3): 1056-62. https://doi.org/10.1016/j.jtcvs.2017.03.154.

Rudiger A, Begdeda H, Babic D, Krüger B, Seifert B, Schubert M, et al. Intraoperative events during cardiac surgery are risk factors for the development of delirium in the ICU. Crit Care. 2016;20(1):264. https://doi.org/10.1186/s13 054-016-1445-8.

Schol PB, Terink IM, Lancé MD, Scheepers HC. Liberal or restrictive fluid management during elective surgery: a systematic review and meta-analysis. J Clin Anesth. 2016;35:26-39. https://doi.org/10.1016/j.jclinane.2016.07.010.

Shin CH, Long DR, McLean D, Grabitz SD, Ladha K, Timm FP, et al. Effects of intraoperative fluid management on postoperative outcomes: a hospital registry study. Ann Surg. 2018;267(6):1084-92. https://doi.org/10.1097/SLA. 0000000000002220

Siemionow K, Cywinski J, Kusza K, Lieberman I. Intraoperative fluid therapy and pulmonary complications. Orthopedics. 2012a;35(2):e184-91. https://doi.org/1 0.3928/01477447-20120123-06

Siemionow K, Pelton MA, Hoskins JA, Singh K. Predictive factors of hospital stay in patients undergoing minimally invasive transforaminal lumbar interbody fusion and instrumentation. Spine (Phila Pa 1976). 2012b;37:2046-54. https:// doi.org/10.1097/BRS.0b013e31825c6688.

Steward DJ. A simplified scoring system for the post-operative recovery room. Can Anaesth Soc J. 1975;22(1):111-3. https://doi.org/10.1007/BF03004827.

Tapia B, Garrido E, Cebrian JL, Del Castillo JL, Gonzalez J, Losantos I, et al. Impact of goal directed therapy in head and neck oncological surgery with microsurgical reconstruction: free flap viability and complications. Cancers (Basel). 2021;13(7):1545. https://doi.org/10.3390/cancers13071545.

van Waes JA, van Klei WA, Wijeysundera DN, van Wolfswinkel L, Lindsay TF, Beattie WS. Association between intraoperative hypotension and myocardial injury after vascular surgery. Anesthesiology. 2016;124(1):35-44. https://doi. org/10.1097/ALN.0000000000000922.

Wang X, Feng K, Liu H, Liu Y, Ye M, Zhao G, et al. Regional cerebral oxygen saturation and postoperative delirium in endovascular surgery: a prospective cohort study. Trials. 2019;20(1):504. https://doi.org/10.1186/s13063-019-3586-y.

Witlox J, Eurelings LS, de Jonghe JF, Kalisvaart KJ, Eikelenboom P, van Gool WA. Delirium in elderly patients and the risk of postdischarge mortality, institutionalization, and dementia: a meta-analysis. JAMA. 2010;304(4):443-51. https://doi.org/10.1001/jama.2010.1013.

Wrzosek A, Jakowicka-Wordliczek J, Zajaczkowska R, Serednicki WT, Jankowski M, Bala MM, et al. Perioperative restrictive versus goal-directed fluid therapy for adults undergoing major non-cardiac surgery. Cochrane Database Syst Rev. 2019;12:CD012767. https://doi.org/10.1002/14651858.CD012767.pub2.

Yang SY, Shim JK, Song Y, Seo SJ, Kwak YL. Validation of pulse pressure variation and corrected flow time as predictors of fluid responsiveness in patients in the prone position. Br J Anaesth. 2013;110(5):713-20. https://doi.org/10.1093/ bja/aes475.

Zhang J, Qiao H, He Z, Wang Y, Che X, Liang W. Intraoperative fluid management in open gastrointestinal surgery: goal-directed versus restrictive. Clinics (Sao Paulo). 2012;67:1149-55. https://doi.org/10.6061/clinics/2012(10)06.

Zhang N, Liang M, Zhang DD, Xiao YR, Li YZ, Gao YG, et al. Effect of goaldirected fluid therapy on early cognitive function in elderly patients with spinal stenosis: a case-control study. Int J Surg. 2018;54(Pt A):201-5. https:// doi.org/10.1016/j.jjsu.2018.04.007.

\section{Publisher's Note}

Springer Nature remains neutral with regard to jurisdictional claims in published maps and institutional affiliations.

Ready to submit your research? Choose BMC and benefit from:

- fast, convenient online submission

- thorough peer review by experienced researchers in your field

- rapid publication on acceptance

- support for research data, including large and complex data types

- gold Open Access which fosters wider collaboration and increased citations

- maximum visibility for your research: over $100 \mathrm{M}$ website views per year

At BMC, research is always in progress.

Learn more biomedcentral.com/submissions 